\title{
Action Potential Initiation and Propagation in Layer 5 Pyramidal Neurons of the Rat Prefrontal Cortex: Absence of Dopamine Modulation
}

\author{
Allan T. Gulledge and Greg J. Stuart \\ Division of Neuroscience, John Curtin School of Medical Research, Australian National University, Canberra, ACT 0200, Australia, and Physiology Institute, \\ University of Freiburg, 79104, Freiburg, Germany
}

\begin{abstract}
Somatic and dendritic whole-cell recording was used to examine action potential (AP) initiation and propagation in layer 5 pyramidal neurons of the rat prelimbic prefrontal cortex. APs generated by somatic current injection, or via antidromic stimulation, were reliably recorded at apical dendritic locations as far as $480 \mu \mathrm{m}$ from the soma. Although the backpropagation of single APs into the apical dendrite was robust, frequency-dependent attenuation was observed during AP trains delivered at $10-100 \mathrm{~Hz}$. APs were usually initiated close to the soma (presumably in the axon); however, strong depolarizing input to the apical dendrite could generate dendritic spikes that preceded somatic APs. AP backpropagation was dependent solely on activation of dendritic voltage-gated sodium channels and did not require activation of dendritic calcium channels. Despite not playing a role in AP backpropagation, calcium-imaging experiments demonstrated that dendritic calcium channels are activated by backpropagating APs, leading to transient increases in intracellular calcium. In addition, calcium imaging revealed that AP backpropagation into the distal apical tuft was frequency dependent. Finally, we tested whether dopamine, a prominent neuromodulator associated with prefrontal activity, could alter AP initiation or backpropagation. Bath-applied dopamine (10 or $100 \mu \mathrm{M})$ did not effect AP backpropagation, frequency-dependent depression, local dendritic spike initiation, or AP-induced calcium signaling. These data indicate that AP backpropagation in prefrontal layer 5 pyramidal neurons is robust but frequency dependent in the distal tuft, requires dendritic sodium rather than calcium channel activation, and, unlike other aspects of neuronal excitability, insensitive to modulation by dopamine.
\end{abstract}

Key words: prefrontal cortex; apical dendrite; action potential; working memory; dopamine; rat; calcium imaging

\section{Introduction}

During the past decade, it has become apparent that the apical dendrites of cortical pyramidal neurons in the somatosensory cortex and hippocampus express voltage-gated channels that allow active backpropagation of axonally generated action potentials (APs) into the apical dendritic tree (Stuart and Sakmann, 1994; Spruston et al., 1995; Stuart et al., 1997). These backpropagating APs have important physiological consequences for synaptic integration (Häusser et al., 2001) and plasticity (Linden, 1999). In addition, the interaction of backpropagating APs with active dendritic conductances or concurrent synaptic input has been shown to promote high-frequency burst firing in pyramidal neurons (Schiller et al., 1997; Schwindt and Crill, 1997; Larkum et al., 1999a; Magee and Carruth, 1999; Williams and Stuart, 1999).

One cell type in which phasic periods of high-frequency AP firing are thought to have important functional consequences is

\footnotetext{
Received July 4, 2003; revised 0ct. 13, 2003; accepted 0ct. 14, 2003.

This work was supported by an International Research Fellow Award from the National Science Foundation, the Wellcome Trust, and the Alexander von Humboldt Foundation.

Correspondence should be addressed to Greg J. Stuart, Division of Neuroscience, John Curtain School of Medical Research, Building 54, Australian National University, Canberra, ACT 0200, Australia. E-mail: greg.stuart@anu.edu.au.

Copyright $\odot 2003$ Society for Neuroscience $\quad 0270-6474 / 03 / 2311363-10 \$ 15.00 / 0$
}

the pyramidal neuron in the prefrontal cortex. This cortical area is critical for a form of short-term memory known as "working memory." Unlike other types of memory such as episodic, semantic, or fear-conditioned memory, working memory is not thought to require permanent changes in the synaptic strength of connections between neurons (i.e., long-term synaptic plasticity). Rather, working memory is believed to involve encoding of behaviorally relevant information in the sustained activity of specific subsets of prefrontal pyramidal neurons (Goldman-Rakic, 1995). This reverberatory activity has been proposed to be dependent on modulation of specific voltage-dependent membrane conductances in the somata and dendrites of prefrontal neurons (Yang and Seamans, 1996; Durstewitz et al., 2000). However, the active dendritic properties of these neurons have not been fully characterized. Although previous studies have noted the presence of dendritic voltage-activated sodium and calcium channels in prefrontal pyramidal neurons (Seamans et al., 1997; GonzalezBurgos and Barrionuevo, 2001), their potential physiological role in action potential initiation or backpropagation has not been explored.

It has been hypothesized that dopaminergic regulation of active dendritic conductances may be important for modifying the excitability and overall firing rates of prefrontal pyramidal neurons during behavioral tasks requiring working memory (Yang 
and Seamans, 1996; Durstewitz et al., 2000; Dreher et al., 2002). Although there is little direct evidence for this hypothesis, modulation of dendritic channels by dopamine would be expected to have important consequences for synaptic integration in these neurons. Dopamine has been shown to modulate voltageactivated sodium and calcium channels in prefrontal neurons (Geijo-Barrientos and Pastore, 1995; Yang and Seamans, 1996; Gorelova and Yang, 2000; Maurice et al., 2001), and thus could, in principle, regulate the initiation and active backpropagation of APs into the dendrites of these neurons.

We used dual whole-cell recording and calcium-imaging techniques to directly test the hypothesis that the apical dendrites of prefrontal layer 5 pyramidal neurons express active conductances capable of supporting AP backpropagation and dendritic spike generation. In addition, we investigate whether dopamine, a prominent neuromodulator associated with prefrontal activity, can modulate active dendritic properties in these neurons.

\section{Materials and Methods}

After halothane anesthesia and decapitation, the brains of 3- to 5-weekold Wistar rats were removed into an ice-cold solution containing (in m) : $125 \mathrm{NaCl}, 25 \mathrm{NaHCO}_{3}, 3 \mathrm{KCl}, 1.25 \mathrm{NaH}_{2} \mathrm{PO}_{4}, 1 \mathrm{CaCl}_{2}, 6 \mathrm{MgCl}_{2}$, and 25 glucose (bubbled with $95 \% \mathrm{O}_{2} / 5 \% \mathrm{CO}_{2}$ ). Coronal brain slices (300 $\mu \mathrm{m}$ thick) containing the prelimbic prefrontal cortex were made using a vibrating tissue slicer (Dosaka, Kyoto, Japan) and were incubated for 30-45 min in a similar solution containing $2 \mathrm{mM} \mathrm{CaCl}_{2}$ and $1 \mathrm{~mm}$ $\mathrm{MgCl}_{2}$ heated to $35^{\circ} \mathrm{C}$. Slices were subsequently stored at room temperature for up to $6 \mathrm{hr}$ before being placed, as needed, into the recording chamber where they were perfused with the $2 \mathrm{mM} \mathrm{CaCl}_{2} / 1 \mathrm{mM} \mathrm{MgCl}_{2}$ solution heated to $35^{\circ} \mathrm{C}$.

Whole-cell somatic and dendritic current-clamp recordings were made under visual control from layer 5 pyramidal neurons in prelimbic prefrontal cortex using methods described previously (Stuart et al., 1993) and BVC-700 current-clamp amplifiers (Dagan, Minneapolis, MN). Recording pipettes (4-10 M $\Omega$ ) were filled with an internal solution containing (in $\mathrm{mm}$ ): $135 \mathrm{~K}$-gluconate, $7 \mathrm{NaCl}, 2 \mathrm{MgCl}_{2}, 10 \mathrm{HEPES}, 2$ $\mathrm{Na}_{2} \mathrm{ATP}, 0.3 \mathrm{NaGTP}$, pH $7.2(\mathrm{KOH})$. After adjustment of capacitance neutralization, compensated whole-cell series resistance was generally between 20 and $40 \mathrm{M} \Omega$ and stable throughout recordings. Cells that showed large changes in series resistance were discarded for data analysis purposes. Membrane potentials were corrected for the liquid junction potential $(12 \mathrm{mV})$ and rounded to the nearest millivolt. Voltage and current signals were filtered at $10 \mathrm{kHz}$ and acquired at 30 or $50 \mathrm{kHz}$ using an ITC-16 interface (InstruTech, Port Washington, NY) controlled by an Apple PowerPC running Axograph software (Axon Instruments, Foster City, CA). Data are presented as mean \pm SEM. Statistical analysis used the Student's $t$ test.

APs were generated via current injection through the somatic or dendritic recording pipette or via antidromic stimulation. Antidromic stimulation was achieved using a patch pipette filled with extracellular saline placed near the axon of the neuron of interest. Stimuli $(50 \mu \mathrm{sec})$ were generated using a custom-built stimulation isolation unit. Unless otherwise stated, APs were generated at $0.05-0.1 \mathrm{~Hz}$. AP amplitude was measured from threshold when induced by current injection and from the resting potential when generated with antidromic stimulation.

For calcium imaging, neurons were loaded with the calcium-sensitive dye Oregon Green BAPTA-1 (200 $\mu \mathrm{M}$; Molecular Probes, Eugene, OR) and visualized using a confocal microscope (LSM 510; Zeiss, Thornwood, NY). Line scans ( $0.5-1 \mathrm{kHz}$ temporal resolution) were made at the indicated somatic and dendritic locations once per minute, and APs were generated via somatic current injection. Raw data were background subtracted, and the change in fluorescence relative to the resting fluorescence $(\Delta F / F)$ was calculated using a $100-200 \mathrm{msec}$ baseline before somatic current injection. In control experiments, we observed a progressive decrease in $\Delta F / F$ over time (mean change in $\Delta F / F$ after 20 trials for single APs, $-44 \pm 7 \%$; for trains of five APs, $-47 \pm 6 \%$; $n=3$ ), which presumably occurred because of a time-dependent increase in dye concentration. Therefore, to assess the potential effect of drug applications on calcium signaling, we compared the average $\Delta F / F$ recorded during drug application with the average of control trials obtained before and after drug application.

Drugs (Sigma, St. Louis, MO) were focally or bath applied at the following concentrations: TTX, $1 \mu \mathrm{M}$; $\mathrm{CdCl}_{2}, 200 \mu \mathrm{M}$; kynurentic acid, 3 $\mathrm{mm}$; bicuculline methiodide, $20 \mu \mathrm{M}$; dopamine, 10 or $100 \mu \mathrm{M}$; and nomifensine, $1 \mu \mathrm{M}$. Bath-applied dopamine was made fresh daily and always included ascorbate $(10 \mu \mathrm{M})$ to reduce oxidation. For focal dendritic drug applications, drugs were dissolved in extracellular saline and loaded into a patch pipette positioned $\sim 20 \mu \mathrm{m}$ proximal to the dendritic recording site. $\mathrm{CdCl}_{2}$ was dissolved and applied in saline lacking $\mathrm{NaH}_{2} \mathrm{PO}_{4}$. Only one cell receiving a single drug treatment was used from each slice.

\section{Results}

\section{Action potential backpropagation}

AP initiation and propagation was investigated in layer 5 pyramidal neurons from prefrontal prelimbic cortex using dual wholecell recordings from the soma and apical dendrite (up to $480 \mu \mathrm{m}$ from the soma). In our slices, the apical dendrites of pyramidal neurons ranged in length from $\sim 500-800 \mu \mathrm{m}$ (including the apical tuft), depending on the superior-inferior location of the soma. Therefore, our most distal dendritic recordings correspond to measurements from the distal part of the apical dendrite near the base of the apical tuft. Somatic current injections (500 msec) were used to evoke action potentials that were recorded simultaneously at somatic and dendritic locations (Fig. 1A,B). When generated in this way, APs were always observed to occur first at the soma and subsequently at the apical dendritic recording site (Fig. $1 \mathrm{~B})$. Average peak-to-peak conduction velocity was $0.47 \pm 0.03 \mathrm{~m} / \mathrm{sec}$ (Fig. $1 C, D$ ), which is similar to that found previously in layer 5 pyramidal neurons from somatosensory cortex under similar recording conditions $(0.5 \mathrm{~m} / \mathrm{sec} ; 4$-week-old rats; $35^{\circ} \mathrm{C}$ ) (Stuart et al., 1997). AP propagation in apical dendrites was robust, with APs showing only modest attenuation with distance from the soma (Fig. 1E). At distances from 420$480 \mu \mathrm{m}$ from the soma, dendritically recorded APs had amplitudes that were $57 \pm 7 \%$ of their somatic values $(n=4$; compare with $\sim 50 \%$ attenuation at $500 \mu \mathrm{m}$ in somatosensory layer 5 pyramidal neurons) (Stuart et al., 1997). Attenuation of steady-state somatic voltage (Fig. $1 F$ ) was significantly greater than AP backpropagation (steady-state attenuation at distances $>420 \mu \mathrm{m}$, $78 \pm 3 \% ; n=4 ; p<0.05)$, indicating that AP backpropagation is active.

\section{Frequency dependence of backpropagation}

Backpropagating APs in both CA1 (Callaway and Ross, 1995; Spruston et al., 1995) and somatosensory layer 5 (Stuart et al., 1997; Williams and Stuart, 1999; Larkum et al., 1999b, 2001) pyramidal neurons are sensitive to the frequency of AP generation, showing increased attenuation during high-frequency AP trains attributable to cumulative sodium channel inactivation (Colbert et al., 1997; Jung et al., 1997). To test for frequencydependent depression of backpropagating APs, we used antidromic stimulation to produce trains of $10 \mathrm{APs}$ at 10,20,50, and $100 \mathrm{~Hz}$. Backpropagating APs were recorded at dendritic locations up to $335 \mu \mathrm{m}$ from the soma (Fig. 2) $(n=11)$. During AP trains, the amplitude of successive APs decreased, with the extent of this decrease dependent on AP frequency (Fig. 2A,B). The amount of frequency-dependent depression, quantified as the ratio of the amplitude of the tenth AP relative to that of the first, was also dependent on the distance of the dendritic recording from the soma (Fig. 2C), with distal locations showing the greatest frequency-dependent attenuation. In contrast to layer 5 pyra- 
A
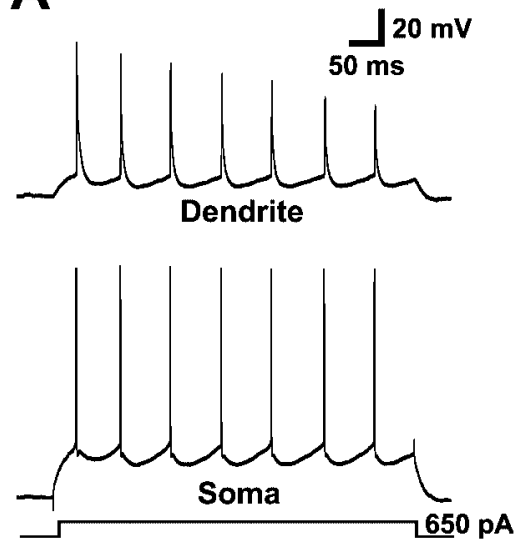

B

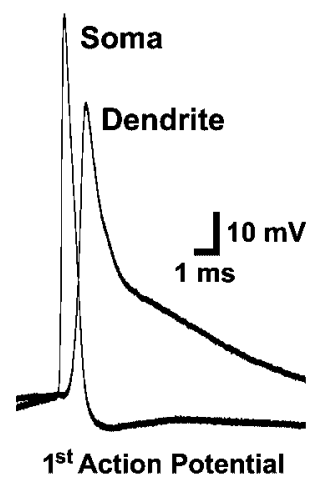

C

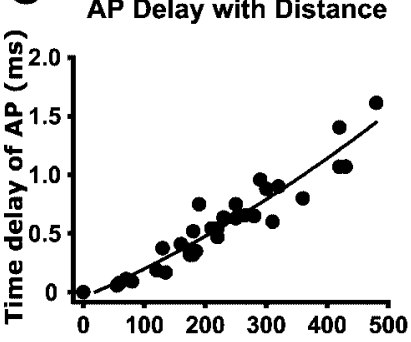

Distance from soma ( $\mathrm{mm})$
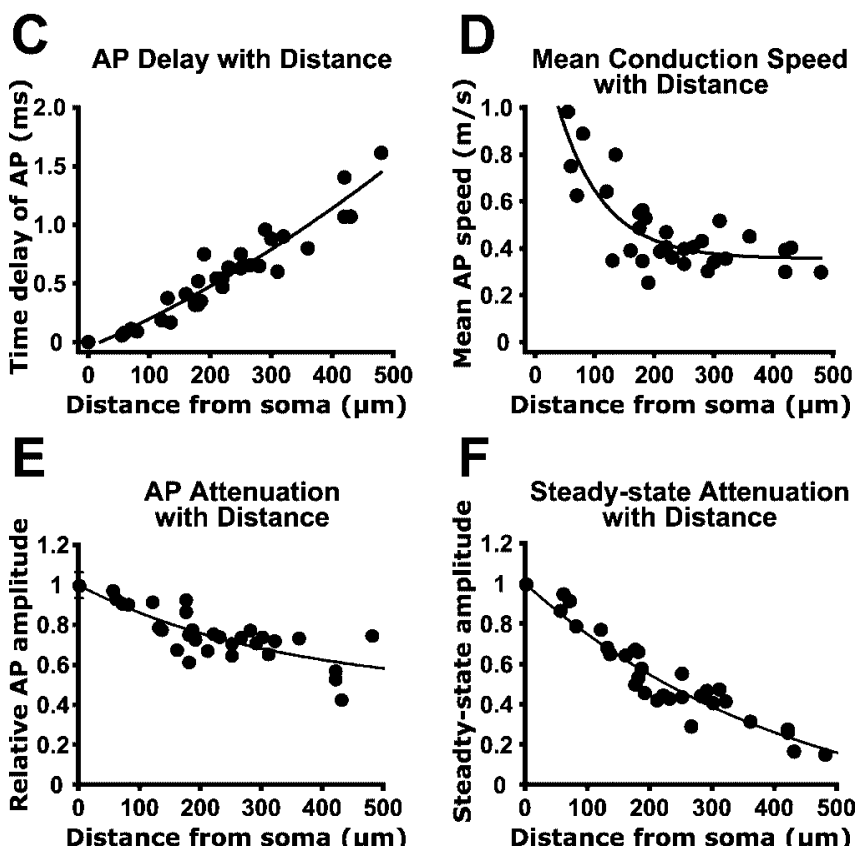

$\mathbf{F}$

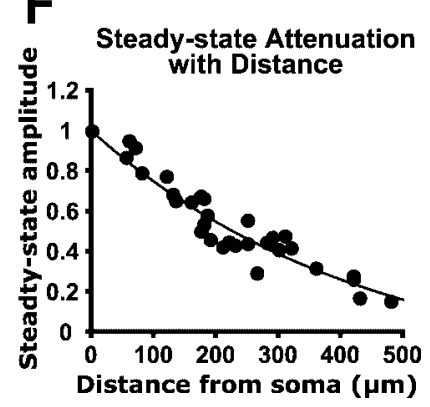

Figure 1. Properties of AP backpropagation in prefrontal pyramidal neurons. $A$, Whole-cell recordings from the soma (bottom) and apical dendrite (top; $360 \mu \mathrm{m}$ from the soma) during AP trains generated by depolarizing current steps $(500 \mathrm{msec} ; 650 \mathrm{pA})$ delivered via the somatic recording electrode. $B$, The first APs from the trains shown in $A$ were enlarged to demonstrate that APs were recorded first at the soma and subsequently in the apical dendrite. C, Time delay between somatic and dendritic AP peak versus distance from the soma. D, Mean AP conduction velocity versus distance from the soma. $E$, Plot of AP attenuation with distance from the soma. $F$, Plot of steady-state attenuation with distance from the soma. $C-F, n=31$.

midal neurons from somatosensory cortex (Stuart et al., 1997; Williams and Stuart, 1999; Larkum et al., 1999b, 2001), highfrequency AP firing was not associated with any obvious dendritic calcium electrogenesis even at the most distal dendritic locations (Fig. 2A).

Role of sodium and calcium channels in backpropagation Previous work in pyramidal neurons from the CA1 region of the hippocampus (Spruston et al., 1995) and somatosensory cortex (Stuart and Sakmann, 1994) indicates that AP backpropagation into apical dendrites depends on activation of dendritic voltageactivated sodium channels. To determine whether dendritic sodium channels participate in AP backpropagation in prefrontal cortex layer 5 pyramidal neurons, we focally applied TTX $(1 \mu \mathrm{M})$ to the apical dendrite just proximal to the site of dendritic record-
A
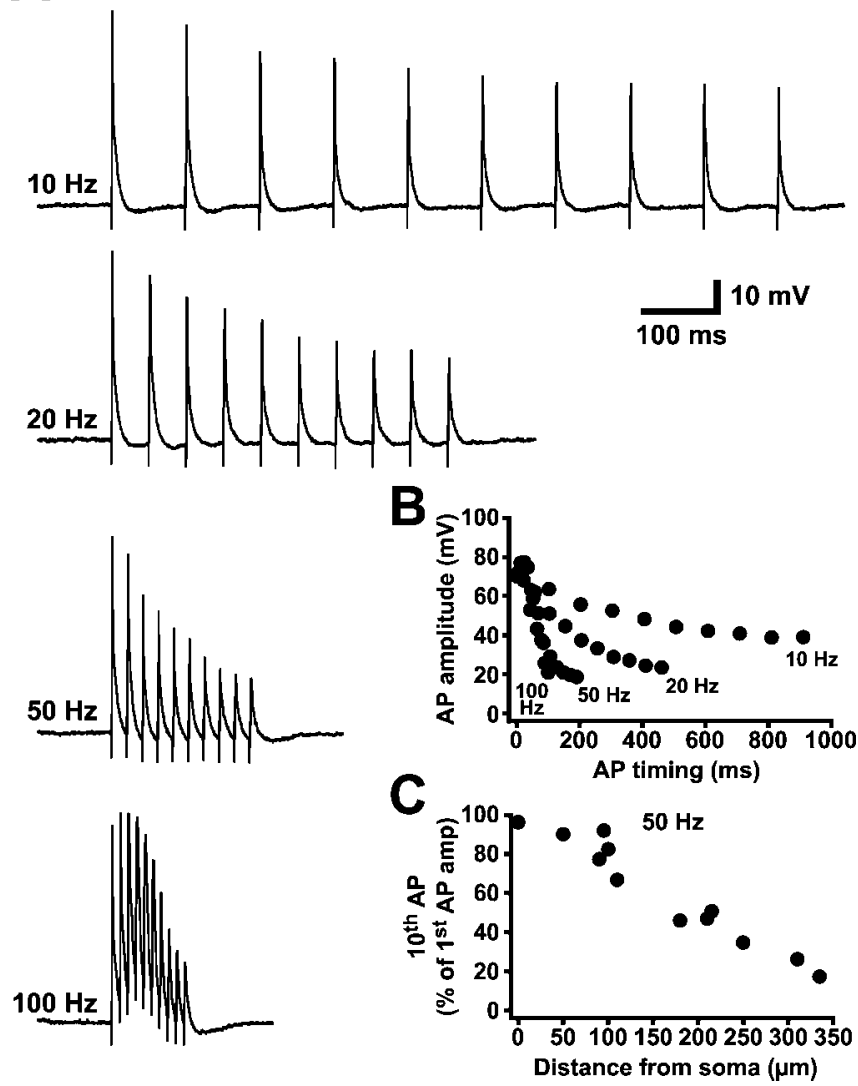

Figure 2. AP backpropagation is frequency dependent. $A$, Dendritic recordings (310 $\mu \mathrm{m}$ from the soma) of AP trains generated by antidromic stimulation at frequencies of 10, 20,50, and $100 \mathrm{~Hz}$. B, Plot of AP amplitude versus timing for the trains shown in A. C, Ratio of the amplitude of the tenth versus first AP during $50 \mathrm{~Hz}$ trains as a function of distance from the soma $(n=11)$.

ing (Fig. $3 A$ ). In these experiments, local TTX application reduced AP amplitude by $66 \pm 3 \%$ while having a negligible effect on somatic AP amplitude (mean change, $1.2 \pm 0.4 \% ; n=5$ ). These data indicate that activation of TTX-sensitive dendritic sodium channels is required for AP backpropagation in prefrontal pyramidal neurons.

To test for activation of dendritic calcium channels by backpropagating APs, we compared antidromic APs generated before and during bath application of $\mathrm{CdCl}_{2}(200 \mu \mathrm{M} ; n=12)$ (Fig. 3B). To control for the potential effect of cadmium application on the tonic activation of excitatory and inhibitory dendritic synapses, in six of these experiments we included $3 \mathrm{~mm}$ kynurenic acid and $20 \mu \mathrm{M}$ bicuculline in the recording saline. Because there were no significant differences between results obtained with and without synaptic antagonists, the data were grouped together. Cadmium application caused a small but significant increase in the amplitude of dendritically recorded APs of $6.1 \pm 2.4 \%(n=12 ; p<$ $0.05)$. In addition, while having no significant effect on backpropagating AP rise time (10-90\%; mean change, $-4.5 \pm 3.3 \%$ ) or width at half-amplitude (mean change, $9.7 \pm 8.2 \%$ ), cadmium application significantly increased the width of the late decay phase of the AP (Fig. 3B). When dendritic AP base-width was measured at $15 \%$ of peak amplitude, cadmium application produced a $38 \pm 7 \%$ increase in AP width $(n=12 ; p<0.05)$. These effects of cadmium are opposite to what would be expected if AP backpropagation required activation of dendritic voltage- 


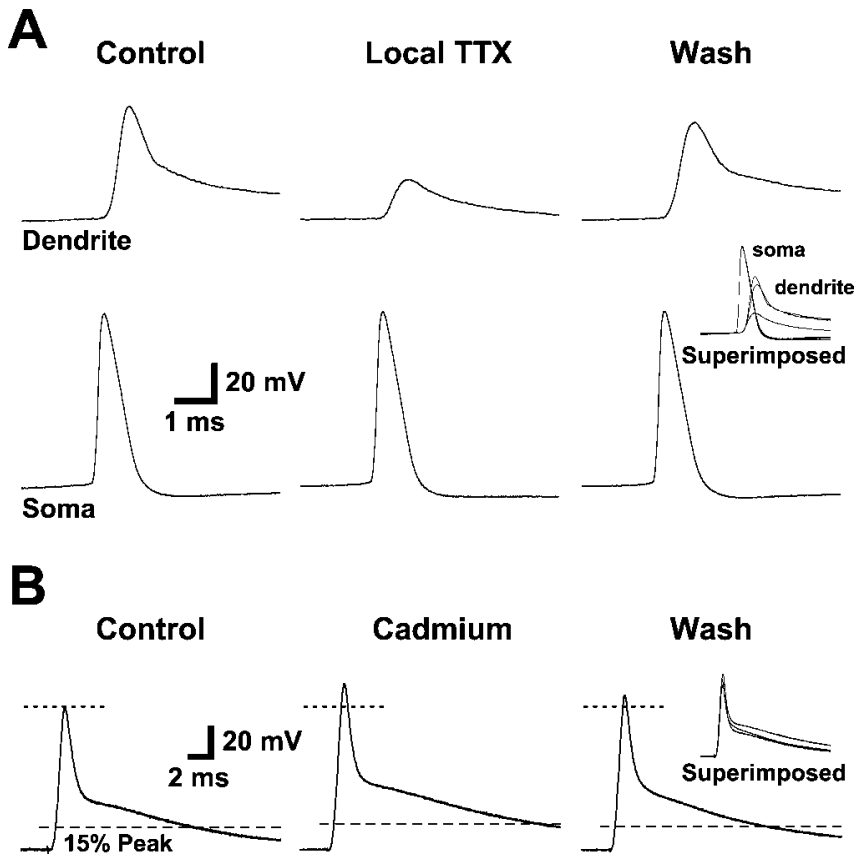

Figure 3. Dendritic propagation of APs is active and requires voltage-gated sodium channels but not calcium channels. A, Somatic (bottom) and dendritic (top; $230 \mu \mathrm{m}$ from the soma) recordings of somatically generated APs before, during, and after local dendritic application of TTX (1 $\mu \mathrm{m}$ ). Inset, Superimposed traces. B, Dendritic recording (205 $\mu \mathrm{m}$ from the soma) of antidromically generated APs before (left), during (middle), and after (right) bath application of cadmium (200 $\mu \mathrm{m})$. Note the increased amplitude and base-width at 15\% amplitude. Inset, Superimposed traces.

activated calcium channels. The small increase in dendritic AP amplitude in cadmium may be attributable to a nonspecific action of cadmium on fast-inactivating potassium channels (Bekkers, 2000), whereas the increase in dendritic AP base-width is presumably attributable to block of calcium-activated potassium channels. Because cadmium application had similar effects on the $\mathrm{AP}$ at the soma, the changes to backpropagating APs in cadmium are likely to be secondary to changes in the somatic AP waveform. Additional experiments will be required to determine the potential role of dendritic voltage- and calcium-activated potassium channels in regulation of AP backpropagation in prefrontal pyramidal neurons. Despite this complication, our findings with cadmium demonstrate that backpropagating APs do not require activation of dendritic calcium channels. This conclusion is consistent with previous reports showing minimal calcium electrogenesis in the apical dendrites of prefrontal pyramidal neurons (Seamans et al., 1997; Gonzalez-Burgos and Barrionuevo, 2001). Together, the above data demonstrate that active backpropagation of APs into the apical dendrite requires activation of dendritic sodium channels and is not associated with significant dendritic calcium channel activation.

\section{Dendritic spike initiation}

When the apical dendrites of somatosensory or CA1 hippocampal pyramidal neurons are sufficiently depolarized, local regenerative events can occur that precede somatic AP generation (Schiller et al., 1997; Stuart et al., 1997; Golding and Spruston, 1998). In somatosensory or CA1 pyramidal neurons, these local dendritic spikes are mediated by the activation of dendritic sodium and calcium channels. To determine whether strong dendritic depolarization can also initiate dendritic spikes in prefrontal pyramidal neurons, we depolarized dendrites via current

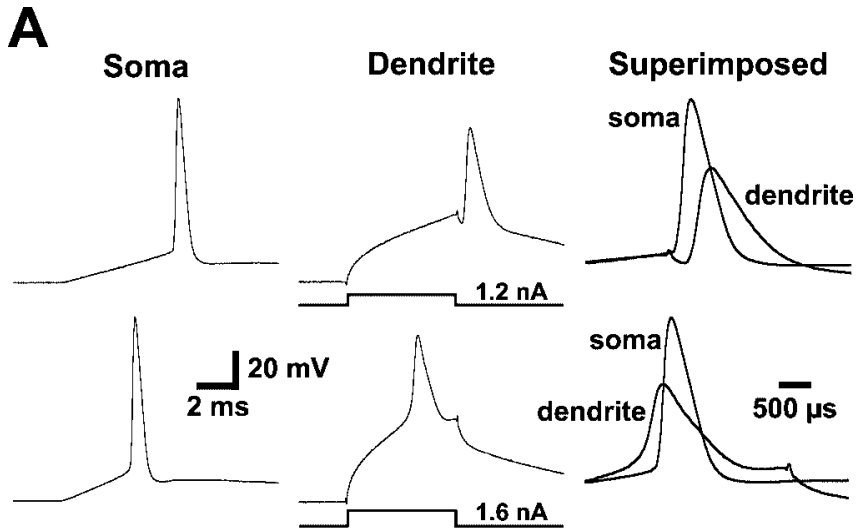

B

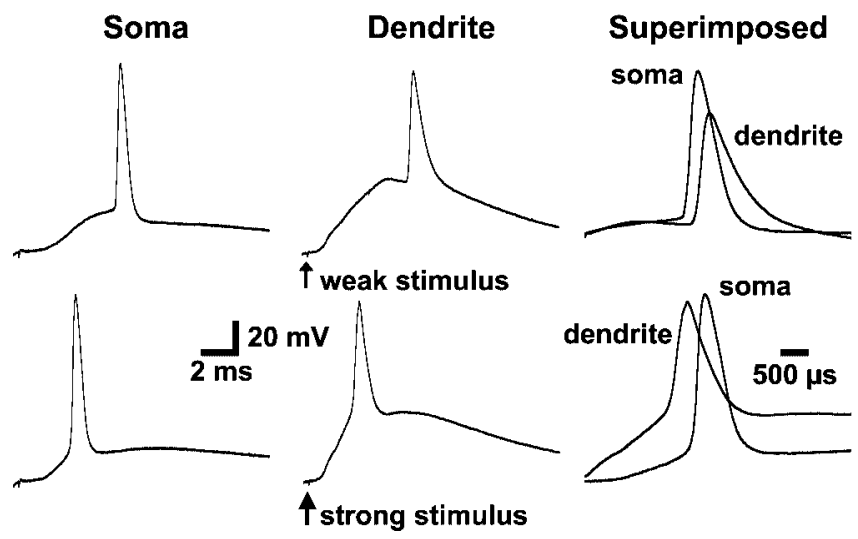

Figure 4. Strong dendritic depolarization can initiate dendritic spikes that precede somatic APs. A, Somatic (left), dendritic (middle; $175 \mu \mathrm{m}$ from the soma), and superimposed (right; note different time scale bar) recordings of APs generated by just-suprathreshold dendritic current injection (top) or a larger dendritic current injection capable of generating a dendritically initiated spike (bottom). B, Somatic (left) and dendritic (middle; $185 \mu \mathrm{m}$ from the soma) responses to weak (top) or strong (bottom) distal dendritic synaptic stimulation (delivered in layer 2/3). The superimposed traces (right; different time scale bar) demonstrate that strong synaptic input can generate dendritic spikes that precede somatic action potentials.

injection through the dendritic recording electrode or via distal synaptic stimulation in layers $2 / 3$ (Fig. 4).

APs generated by brief ( $3-5 \mathrm{msec}$ ) current steps of increasing amplitude via the apical dendritic recording pipette (120-480 $\mu \mathrm{m}$ from the soma) were observed first by the somatic recording pipette and then subsequently by the dendritic recording pipette, indicating an axo-somatic site of AP initiation (Fig. 4A, top). Increasing the magnitude of dendritic current injection led to the initiation of dendritic spikes that preceded somatic APs (Fig. 4A, bottom) $(n=15)$. Similarly, synaptic stimulation delivered to layers $2 / 3$ at low stimulation intensity led to generation of APs that were observed first by the somatic recording pipette and subsequently backpropagated into the dendrites (Fig. $4 B$, top). Increasing the intensity of synaptic stimulation resulted in the initiation of dendritic spikes that preceded somatic APs (Fig. $4 B$, bottom $)(n=7)$. That the synaptic responses in these experiments were of dendritic origin was supported by the observation that EPSPs recorded at dendritic locations (175-480 $\mu \mathrm{m}$ from the soma) were always larger than those detected at the soma $(n=$ 7 of 7 cells). Local dendritic spikes were never observed in isolation and were always followed with a short delay by APs detected at the somatic recording site, suggesting that dendritic spikes in prefrontal pyramidal neurons can propagate to the soma and have a direct impact on axonal AP initiation. 
Table 1. Summary of statistically significant effects of dopamine (10 $\mu \mathrm{M})$ on pyramidal neuron physiology

\begin{tabular}{|c|c|c|c|c|}
\hline & $n$ (control/DA) & Control & $10 \mu \mathrm{M} \mathrm{DA}$ & Change in DA ( $p<0.05$ for all) \\
\hline$V_{M}($ soma $)$ & $37 / 25$ & $-80.4 \pm 0.5 \mathrm{mV}$ & $-78.1 \pm 0.7 \mathrm{mV}$ & $2.5 \pm 0.4 \mathrm{mV}$ \\
\hline$V_{M}$ (dendrite) & $40 / 36$ & $-77.9 \pm 0.6 \mathrm{mV}$ & $-74.8 \pm 0.6 \mathrm{mV}$ & $3.0 \pm 0.4 \mathrm{mV}$ \\
\hline$R_{\mathrm{N}}$ (soma) & 8 & $88 \pm 15 \mathrm{M} \Omega$ & $80 \pm 6 \mathrm{M} \Omega$ & $-7.7 \pm 2.5 \%$ \\
\hline$R_{\mathrm{N}}$ (dendrite) & 11 & $55 \pm 6 \mathrm{M} \Omega$ & $46 \pm 6 \mathrm{M} \Omega$ & $-16.9 \pm 2.0 \%$ \\
\hline Excitability (with depolarization) & 21 & $5.2 \pm 0.4$ spikes & $6.5 \pm 0.8$ spikes & $20 \pm 9 \%$ \\
\hline Excitability (hyperpolarized) & 12 & $5.8 \pm 0.6$ spikes & $2.7 \pm 0.9$ spikes & $-58 \pm 13 \%$ \\
\hline
\end{tabular}

Excitability was measured either during dopamine-induced depolarization (with depolarization) or with the membrane potential adjusted to control levels with a somatic DC bias current (hyperpolarized). Excitability was measured as number of spikes in response to a given somatic current injection $(\sim 300 \mathrm{pA}, 1 \mathrm{sec}) . R_{\mathrm{N}}$, Input resistance; $V_{\mathrm{M}}$, resting membrane potential.

In four cases tested, focal or bath application of cadmium $(200$ $\mu \mathrm{M})$ had no effect on dendritic spikes generated by dendritic current injection, suggesting that, similar to backpropagating APs, dendrite spikes are mediated by voltage-activated sodium channels rather than calcium channel activation (data not shown). Consistent with this observation, the time course of dendritic spikes was similar to that of backpropagating APs (compare Figs. $1 B$ and $4 A$ ). Together, these data demonstrate that strong dendritic depolarizations in prefrontal pyramidal neurons can initiate local dendritic spikes mediated primarily by dendritic sodium channels, and that these dendritic events can directly influence axonal AP generation.

\section{Dopamine does not modulate AP backpropagation}

The above data suggest a critical role for voltage-gated sodium channels in both AP backpropagation and dendritic spike generation in the apical dendrites of prefrontal pyramidal neurons. Dopamine, an important neuromodulator in prefrontal cortex, has been reported to both increase (Yang and Seamans, 1996; Gorelova and Yang, 2000) and decrease (Geijo-Barrientos and Pastore, 1995; Maurice et al., 2001) sodium channel activation in prefrontal pyramidal neurons. As a consequence, dopamine would be expected to modulate AP backpropagation and dendritic spike generation. To test this, we investigated the effect of bath application of dopamine (10 or $100 \mu \mathrm{M} ; 5-10 \mathrm{~min}$ ) on AP backpropagation. As reported previously (Penit-Soria et al., 1987; Geijo-Barrientos and Pastore, 1995; Yang and Seamans, 1996; Shi et al., 1997; Gulledge and Jaffe, 1998, 2001; Wang and O'Donnell, 2001), dopamine application at $10 \mu \mathrm{M}$ induced a variety of effects on prefrontal layer 5 pyramidal neurons in vitro, including depolarization, a decrease in input resistance, and modulation of excitability during somatic current injection ( $\mathrm{Ta}-$ ble 1). Surprisingly, however, dopamine application did not significantly affect AP backpropagation into the apical dendrites of these neurons (Fig. 5). In the presence of dopamine, the amplitudes of dendritically recorded backpropagating APs (50-480 $\mu \mathrm{m}$ from the soma) were $98 \pm 1 \%$ of baseline values (control AP amplitude, $69 \pm 3 \mathrm{mV}$; AP amplitude in dopamine, $68 \pm 3 \mathrm{mV}$; $n=25)$. We also investigated a possible distance dependence to the action of dopamine by comparing changes in AP amplitude and half-width during dopamine application as a function of distance from the soma (Fig. $5 B, C$ ). Dopamine had no significant effect on either dendritic AP amplitude or half-width at distances up to $480 \mu \mathrm{m}$ from the soma. In additional experiments using antidromic stimulation, dopamine also failed to have any significant effect on the width of backpropagating APs at $15 \%$ of peak amplitude (mean change, $-8.4 \pm 3.1 \% ; n=11$ ).

To test whether dopamine had an effect on frequencydependent depression of backpropagating APs, we bath-applied dopamine during high-frequency trains of 10 APs generated at 10, 20, 50, and $100 \mathrm{~Hz}$ (Fig. 6). Because frequency-dependent depression of backpropagating APs is attributable to cumulative
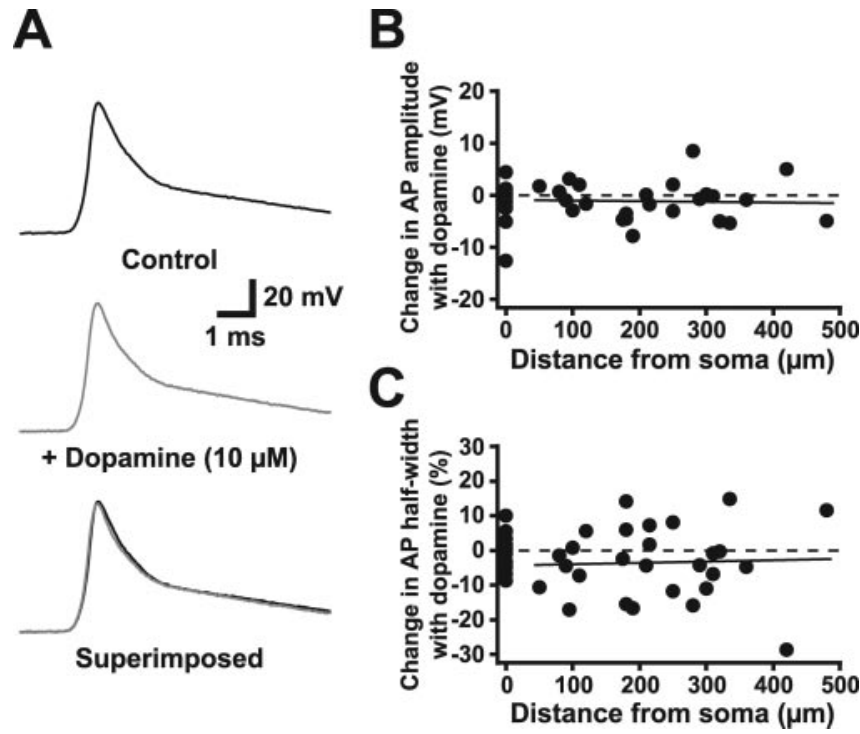

Figure 5. Dopamine does not modulate single backpropagating APs. A, Dendritic recording (360 $\mu \mathrm{m}$ from the soma) of APs generated by somatic current injection before (top) and during (middle) bath application of $10 \mu \mathrm{m}$ dopamine. Superimposed traces (bottom) demonstrate the absence of an effect of dopamine on AP waveform. $B, C$, Change in AP amplitude $(B)$ and half-width $(C$ ) during dopamine application versus distance from the soma. Dashed line represents zero change. Solid lines are linear regression fits to the data.

sodium channel inactivation (Colbert et al., 1997; Jung et al., 1997), one would expect that small changes in sodium channel availability would have a significant effect on the amplitude of backpropagating APs during high-frequency trains. Dopamine applied under these conditions might expose an otherwise modest dopamine-induced modulation of dendritic sodium channels that is insufficient to affect single backpropagation APs. As seen in Figure 6, however, dopamine had no such effect on frequencydependent depression of backpropagating APs $(n=11)$. This was true for all frequencies (Fig. $6 \mathrm{~B}$ ) and at all dendritic recording locations (Fig. 6C).

In the above experiments, $10 \mu \mathrm{M}$ dopamine had no effect on AP backpropagation. However, it is possible that $10 \mu \mathrm{M}$ is not a concentration that is high enough to modulate backpropagating action potentials. To maximally activate dopamine receptors, in six experiments, we bath-applied dopamine at a high concentration $(100 \mu \mathrm{M})$ in the presence of the dopamine uptake blocker nomifensine $(1 \mu \mathrm{M})$. This higher concentration of dopamine had no significant effect on AP backpropagation. Mean change in AP amplitude was $-0.5 \pm 1.1 \%$ at the soma and $-1.6 \pm 0.7 \%$ at dendritic locations (120-410 $\mu \mathrm{m}$ from the soma). Similarly, we observed no significant effect of dopamine $(100+1 \mu \mathrm{M}$ nomifensine) on dendritic AP half-width or rise time $(n=6$; data not shown).

These experiments rule out a role for dopamine in the modu- 
A
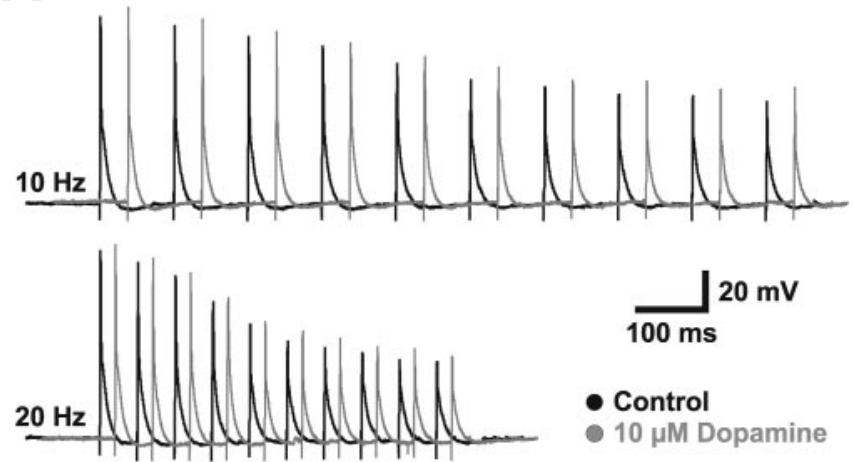

B
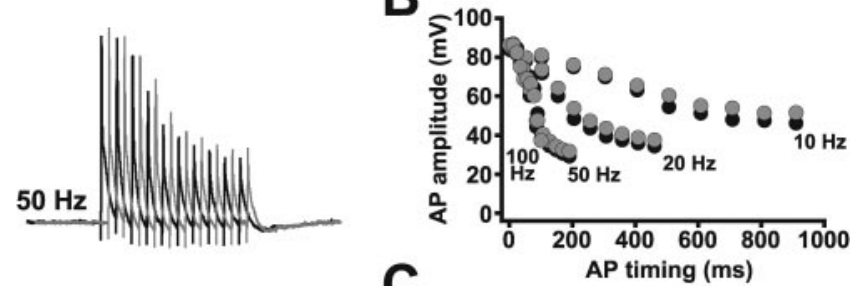

C

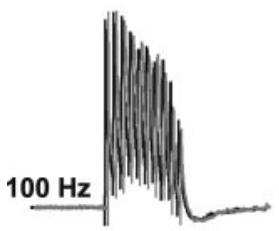

A

A Soma

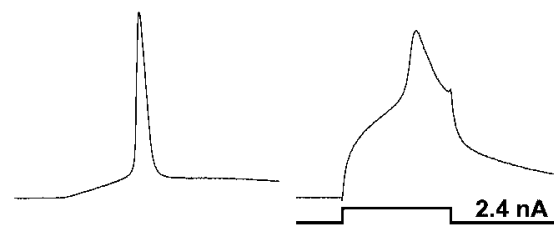

B

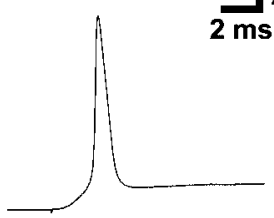

$20 \mathrm{mV}$

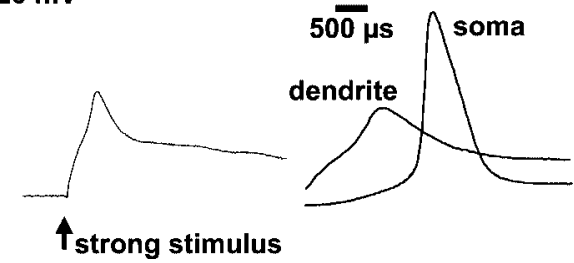

Figure 7. Dopamine does not block initiation of dendritic spikes. $A$, Somatic (left), dendritic (middle; $210 \mu \mathrm{m}$ from the soma), and superimposed (right; note different time scale bar) responses to a strong dendritic current injection in the presence of $10 \mu \mathrm{m}$ dopamine. $B$, Responses from the soma (left) and dendrite (middle; $300 \mu \mathrm{m}$ from the soma) to strong synaptic stimulation delivered to layer $2 / 3$ in the presence of $10 \mu \mathrm{m}$ dopamine. Superimposed traces (right) show a dendritic spike preceding the somatic AP.

primary or secondary branches of the apical tuft (400-600 $\mu \mathrm{m}$ from the soma; $n=5$ ). Somatic current injection was used to generate either single APs or trains of three to five APs $(50 \mathrm{~Hz})$ and line scans used to access changes in fluorescence (Fig. 8 B). As is the case in both hippocampal and somatosensory cortical pyramidal neurons, backpropagating APs generated transient rises in intracellular calcium at all dendritic locations examined (Fig. $8 C$ ). This indicates that backpropagating APs in prefrontal pyramidal neurons activate dendritic voltage-activated calcium channels, although their activation is not required to sustain backpropagation. The magnitude of AP-induced calcium signals was dependent on location, presumably resulting from differences in surface/volume ratio, local dye concentration, and the extent of AP backpropagation. Importantly, in the proximal tuft, we observed that the response to five APs was often similar to, or not much larger than, the response generated by a single AP (Fig. 8C, bottom). This is presumably a consequence of frequencydependent attenuation of AP backpropagation at these locations (Fig. 2).

Previous data suggest that dopamine can downregulate calcium channels in the apical dendrites of prefrontal pyramidal neurons (Yang and Seamans, 1996). We therefore tested the possibility that dopamine might modulate the rise in intracellular calcium generated by backpropagating APs (Fig. 9). To correct for time-dependent decreases in $\Delta F / F$ (Fig. $9 A$ ), which could influence the interpretation of experiments with dopamine, we compared the calcium signals induced by backpropagating APs in the presence of dopamine with the average of AP-induced calcium transients observed before and after dopamine application (Fig. $9 B, C$ ) (see Materials and Methods). As summarized in Figure $9 D$, no significant effect of dopamine was observed on AP-induced calcium influx for either single or multiple APs at any of the tested dendritic locations ( $n=5$ for each location). In separate control experiments, focal TTX application $(1 \mu \mathrm{M})$ to the apical dendrite (200 $\mu \mathrm{m}$ from the soma) reversibly decreased backpropagating AP-induced calcium influx during trains of five APs by $84 \pm 9 \%$ ( $n=3$; data not shown), indicating that changes in backpropagating AP-induced calcium influx can be detected with our system. The absence of an effect of dopamine on back- 

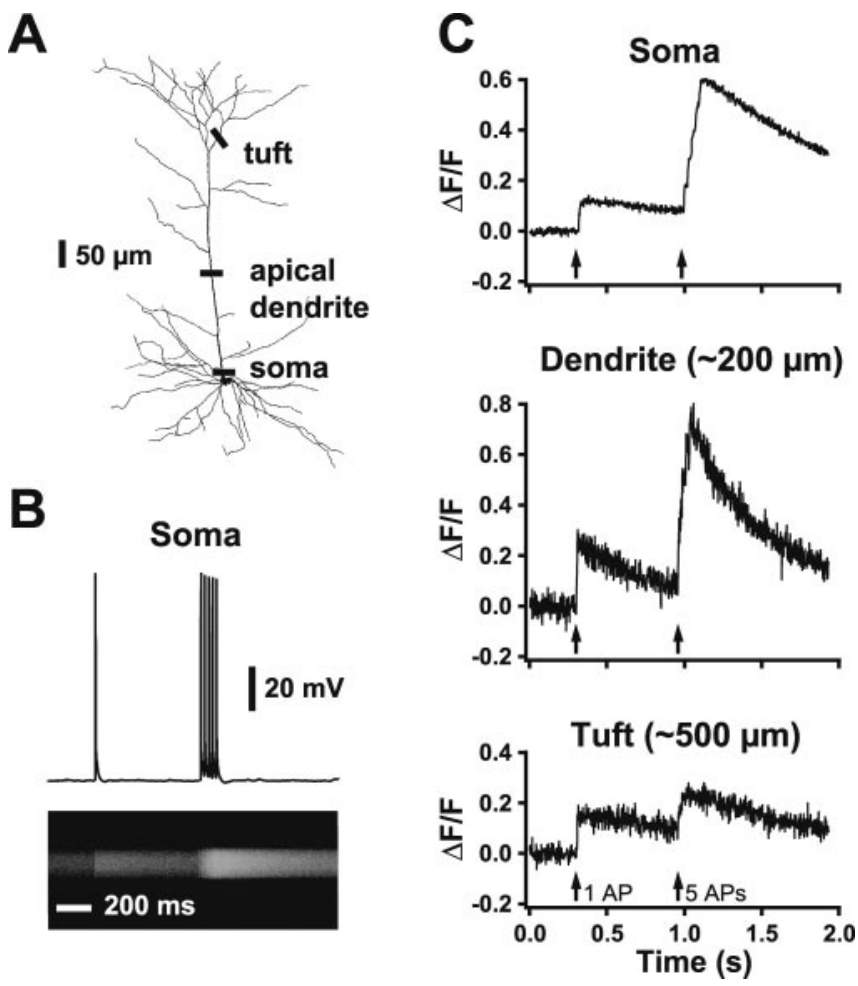

Figure 8. Backpropagating somatic APs cause calcium transients in the apical dendrites of prefrontal neurons. A, A reconstructed prefrontal layer 5 pyramidal neuron showing somatic, dendritic, and tuft locations of line scans used to detect calcium signals in response to somatic APs. B, In a cell filled with Oregon Green BAPTA-1 $(200 \mu \mathrm{M})$, somatic current injection produces APs (top) that result in a calcium-dependent change in fluorescence imaged using a line scan at the intersection of the soma and apical dendrite (bottom). C, Plot of $\Delta F / F$ in response to a similar spike train imaged at three locations: the intersection of the soma and apical dendrite (top), in the apical dendrite (middle; $\sim 200 \mu \mathrm{m}$ from the soma), and in a proximal branch of the apical tuft (bottom; $\sim 500 \mu \mathrm{m}$ from the soma). Data are from three different neurons.

propagating AP-induced calcium influx is consistent with our observation of no effect of dopamine on electrically recorded backpropagating APs. In addition, these imaging data demonstrate that dopamine does not modulate dendritic voltageactivated calcium channels activated by backpropagating APs.

Finally, we explored AP backpropagation into the distal tuft near the outer edge of layer 1 (Fig. 10A) (150-250 $\mu \mathrm{m}$ from the base of the apical tuft). At these distal locations, single APs or AP trains at low frequencies $(50 \mathrm{~Hz})$ failed to produce any observable rise in intracellular calcium. Detectable rises in intracellular calcium were only observed during higher frequency AP bursts (Fig. $10 \mathrm{~B}, \mathrm{C})(3-6 \mathrm{APs}$ at $200 \mathrm{~Hz} ; n=5)$. By analogy with similar findings in layer 5 pyramidal neurons from somatosensory cortex (Larkum et al., 1999b), this suggests that AP backpropagation into the distal tuft of layer 5 pyramidal neurons in the prefrontal cortex is frequency dependent and requires high-frequency (200 $\mathrm{Hz}$ ) AP burst firing. In general, peak $\Delta F / F$ values were smaller at more distal locations and required a greater number of APs in the burst to evoke a detectable rise in calcium (Fig. 10D). In four of these experiments, dopamine $(10 \mu \mathrm{M})$ was bath applied to test for modulation of calcium signaling in the distal tuft. As observed at more proximal locations, dopamine had no significant effect on the occurrence or magnitude of calcium signals at these distal tuft locations (Fig. 10E,F).
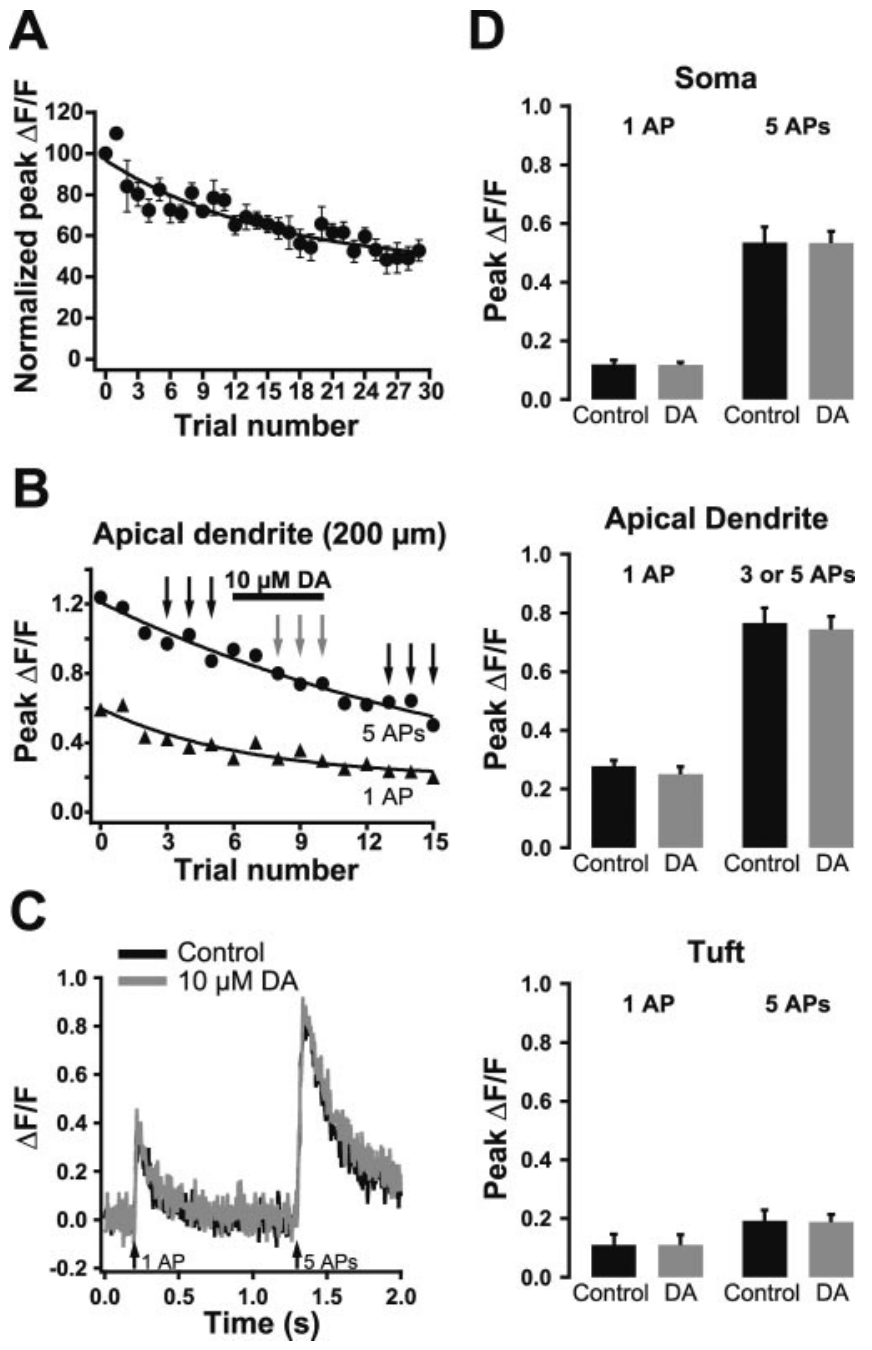

Figure 9. Dopamine does not modulate calcium signaling in the apical dendrite. $A$, Plot of normalized average peak $\Delta F / F( \pm S E M ; n=3)$ in response to somatic APs imaged $200 \mu \mathrm{m}$ from the soma. Note the time-dependent decrease in $\Delta F / F$. $B$, Plot of peak $\Delta F / F$ during single (triangles) and trains of five APs (circles) during dopamine (DA) application at the indicated time (bar). C, Comparison of averaged $\Delta F / F$ traces in control conditions (black; before and after dopamine) and during dopamine application (gray). Traces shown are averages of trials at the times indicated by the black and gray arrows in B.D, Summary graphs showing a lack of effect of dopamine on dendritic calcium transients evoked by single APs or trains of five APs at the soma (top), $200 \mu \mathrm{m}$ into the apical dendrite (middle), and in the proximal apical tuft (bottom).

\section{Discussion}

Active propagation in dendrites

The ability of axonally generated APs to actively propagate into dendrites has been assessed in a number of neuronal types from a variety of brain regions and has been found to be strongly dependent on the specific type of neuron studied. Some neurons, such as cerebellar Purkinje cells, exhibit no active AP backpropagation (Stuart and Häusser, 1994), whereas other neurons, such as midbrain dopaminergic neurons (Häusser et al., 1995) and mitral cells in the olfactory cortex (Bischofberger and Jonas, 1997; Chen et al., 1997), show robust nondecremental AP backpropagation. Pyramidal neurons from the somatosensory cortex and CA1 region of the hippocampus exhibit moderate AP propagation (Stuart and Sakmann, 1994; Spruston et al., 1995), which is strongly dependent on ion channel expression and morphology (Magee and Carruth, 1999; Golding et al., 2001; Vetter et al., 2001; Tsay and Yuste, 2002). 


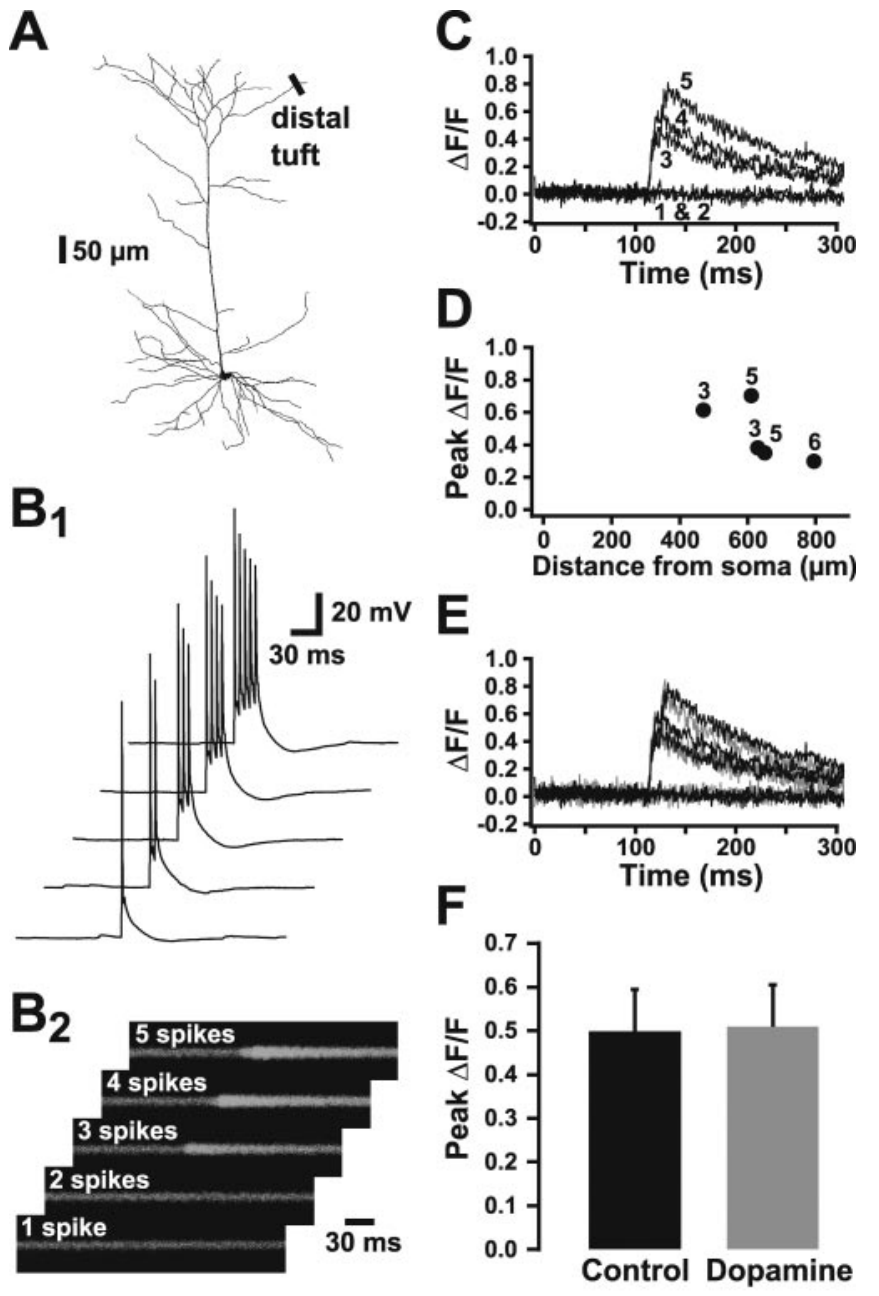

Figure 10. AP backpropagation into the distal tuft is frequency dependent. $A$, Reconstructed prefrontal layer 5 pyramidal neuron showing location of line scans in the distal apical tuft (470-780 $\mu \mathrm{m}$ from the soma). $B, 0$ ne to five APs at $200 \mathrm{~Hz}$ were generated by brief somatic current injections $\left(B_{1}\right)$, whereas simultaneous line scans taken across dendrites in the distal apical tuft produce the corresponding calcium transients $\left(B_{2}\right)$. C, Plots of average $\Delta F / F$ for five trials similar to that shown in $B$. Numbers refer to somatic APs generated per trial. Note that a detectable calcium signal is only observed during bursts of three or more APs. D, Plot of peak $\Delta F / F$ during high-frequency AP bursts as a function of distance from the soma. The numbers indicate the minimum number of APs needed to evoke a detectable calcium signal at each location. $E$, Plot of average $\Delta F / F$ during AP bursts of three to six $\operatorname{APs}(200 \mathrm{~Hz})$ under control conditions (black) and during bath application of $10 \mu \mathrm{m}$ dopamine (gray). F, Summary of peak $\Delta F / F$ in control and dopamine $(10 \mu \mathrm{m} ; n=4)$ conditions at distal tuft locations during highfrequency AP bursts. The minimum number of APs needed to evoke a detectable calcium signal under control conditions was used for comparison of control and dopamine responses.

Here, we show that the apical dendrites of layer 5 pyramidal neurons of the prefrontal cortex are also capable of supporting active AP backpropagation, suggesting that AP backpropagation may be a common feature of all pyramidal neurons. AP backpropagation into the apical dendrites of prefrontal neurons was found to have several characteristics similar to AP backpropagation observed in somatosensory cortex. Backpropagating AP conduction speed and magnitude of AP attenuation during single APs, as well as AP-induced calcium influx, were similar to previous findings in somatosensory layer 5 pyramidal neurons (Schiller et al., 1995; Stuart et al., 1997). In addition, AP backpropagation into the most distal dendrites was found to be frequency dependent, requiring high-frequency AP bursts, as is the case in distal dendrites of pyramidal neurons from somatosen- sory cortex (Larkum et al. 1999b; Williams and Stuart, 2000). In contrast, we found no evidence for either dendritic calcium electrogenesis during high-frequency AP firing or initiation of dendritic calcium spikes, which are common features of the distal apical dendrites of layer 5 pyramidal neurons from somatosensory cortex (Amitai et al., 1993; Kim and Connors, 1993; Schiller et al., 1995; Stuart et al., 1997; Larkum et al., 1999a,b, 2001; Williams and Stuart, 1999, 2000, 2002). These differences suggest that dendritic calcium electrogenesis is significantly reduced in prefrontal cortex layer 5 pyramidal neurons in comparison with layer 5 pyramidal neurons from somatosensory cortex. This conclusion is consistent with previous reports of little, if any, calcium electrogenesis in the apical dendrite of prefrontal pyramidal neurons (Seamans et al., 1997; Gonzalez-Burgos and Barrionuevo, 2001).

\section{Lack of modulation by dopamine}

Because dopamine has previously been reported to either facilitate (Yang and Seamans, 1996; Gorelova and Yang, 2000) or depress (Geijo-Barrientos and Pastore, 1995; Maurice et al., 2001) sodium currents in prefrontal pyramidal neurons, we were especially interested in examining the effect of dopamine on AP backpropagation. In our experiments, bath application of dopamine led to changes in resting potential, input resistance, and excitability (Table 1), consistent with the actions of dopamine on prefrontal cortex pyramidal neurons reported previously (Penit-Soria et al., 1987; Geijo-Barrientos and Pastore, 1995; Yang and Seamans, 1996; Shi et al., 1997; Gulledge and Jaffe, 1998, 2001; Wang and O'Donnell, 2001). Despite these actions of dopamine, we observed no change in the amplitude or kinetics of dendritically recorded backpropagating APs or any effect on dendritic spike initiation. In addition, dopamine had no effect on frequencydependent attenuation of backpropagating APs during highfrequency AP trains, in which small changes in dendritic sodium channel availability should be easily detected. Consistent with previous findings (Gulledge and Jaffe, 2001), we also observed no effect of dopamine on the amplitude or kinetics of somatic APs. Together, these data demonstrate that dopamine does not modulate the sodium channels that sustain AP initiation or backpropagation in prefrontal layer 5 pyramidal neurons. Dopamine also fails to modulate sodium channel-dependent boosting of artificial EPSPs generated by current injection into the apical dendrites of prefrontal pyramidal neurons (G. Gonzalez-Burgos, personal communication). The explanation for why we observed no effect of dopamine on AP initiation and backpropagation, despite previous work showing dopaminergic regulation of sodium channels in prefrontal pyramidal neurons (GeijoBarrientos and Pastore, 1995; Yang and Seamans, 1996; Gorelova and Yang, 2000; Maurice et al., 2001), remains to be determined.

Because dopamine has been shown to reduce calcium channel activation in the prefrontal cortex (Yang and Seamans, 1996) as well as other cells types (Sah and Bean, 1994), we suspected that dopamine might depress dendritic calcium transients generated by backpropagating APs. However, calcium imaging experiments demonstrated no such effect of dopamine at any of the dendritic locations examined. Thus, we find no evidence in favor of the notion that dopamine modulates active conductances in the apical dendrites of prefrontal pyramidal neurons. This conclusion is consistent with the finding that dopaminergic input to the prefrontal cortex is made preferentially to the deeper cortical layers, close to the soma of layer 5 neurons, rather than in the superficial layers containing the apical dendrites of these neurons (Berger et al., 1991). However, it should be noted that our data do not rule 
out the possibility that dopamine might modulate AP backpropagation or initiation in more developmentally mature animals (i.e., those more than 5 weeks of age).

\section{Functional implications}

One hypothesis regarding dopaminergic action during working memory tasks is that dopamine "uncouples" inputs to the apical dendrite from the rest of the neuron by downregulating active dendritic conductances (Yang and Seamans, 1996; Durstewitz et al., 2000; Dreher et al., 2002). The data presented here argue against this hypothesis, because we find no evidence for dopamine modulation of the dendritic sodium conductances that support AP backpropagation in prefrontal pyramidal neurons. Furthermore, we find no evidence for modulation of the dendritic calcium conductances activated by backpropagating APs and responsible for AP-induced increases in dendritic calcium.

Although our data suggest that dopaminergic modulation of dendritic conductances does not underlie the persistent activity associated with working memory, AP backpropagation itself may play an important role in maintaining sustained activity in prefrontal pyramidal neurons during the delay periods associated with working memory tasks. Working memory delay periods are associated with irregularly timed high-frequency burst discharges (Compte et al., 2003). Such irregular high-frequency discharges promote AP backpropagation into the distal apical dendrites of somatosensory layer 5 pyramidal neurons (Williams and Stuart, 2000), and our data suggest this is also the case in prefrontal layer 5 pyramidal neurons (Fig. 10). Amplification of AP backpropagation into distal dendrites during high-frequency discharges will increase the interaction of backpropagating APs with concurrent excitatory synaptic input, which could, in principle, further enhance the rate of AP output (Larkum et al., 1999a; Stuart and Häusser, 2001). Such interactions between backpropagating APs and excitatory synaptic inputs onto the distal dendrites of prefrontal pyramidal neurons is likely to be enhanced during working memory tasks, because transient increases in extracellular dopamine (Watanabe et al., 1997) may enhance the NMDA component of excitatory responses (Seamans et al., 2001; Wang and O'Donnell, 2001). In this way, active AP backpropagation in prefrontal pyramidal neurons may facilitate the development and maintenance of persistent activity during tasks requiring working memory.

\section{References}

Amitai Y, Friedman B, Connors BW, Gutnick MJ (1993) Regenerative activity in apical dendrites of pyramidal cells in neocortex. Cereb Cortex 3:26-38.

Bekkers JM (2000) Properties of voltage-gated potassium currents in nucleated patches from large layer 5 cortical pyramidal neurons of the rat. J Physiol (Lond) 525:593-609.

Berger B, Gaspar P, Verney C (1991) Dopaminergic innervation of the cerebral cortex: unexpected differences between rodents and primates. Trends Neurosci 14:21-27.

Bischofberger J, Jonas P (1997) Action potential propagation into the presynaptic dendrites of rat mitral cells. J Physiol (Lond) 504:359-365.

Callaway JC, Ross WN (1995) Frequency-dependent propagation of sodium action potentials in dendrites of hippocampal CA1 pyramidal neurons. J Neurophysiol 74:1395-1403.

Chen WR, Midtgaard J, Shepherd GM (1997) Forward and backward propagation of dendritic impulses and their synaptic control in mitral cells. Science 278:463-467.

Colbert CM, Magee JC, Hoffman DA, Johnston D (1997) Slow recovery from inactivation of $\mathrm{Na}^{+}$channels underlies the activity-dependent attenuation of dendritic action potentials in hippocampal CA1 pyramidal neurons. J Neurosci 17:6512-6521.
Compte A, Constantinidis C, Tegner J, Raghavachari S, Chafee MV, Goldman-Rakic PS, Wang XJ (2003) Temporally irregular mnemonic persistent activity in prefrontal neurons of monkeys during a delayed response task. J Neurophysiol 90:3441-3454.

Dreher JC, Guigon E, Burnod Y (2002) A model of prefrontal cortex dopaminergic modulation during the delayed alternation task. J Cogn Neurosci 14:853-865.

Durstewitz D, Seamans JK, Sejnowski TJ (2000) Dopamine-mediated stabilization of delay-period activity in a network model of prefrontal cortex. J Neurophysiol 83:1733-1750.

Geijo-Barrientos E, Pastore C (1995) The effects of dopamine on the subthreshold electrophysiological responses of rat prefrontal cortex neurons in vitro. Eur J Neurosci 7:358-366.

Golding NL, Spruston N (1998) Dendritic sodium spikes are variable triggers of axonal action potentials in hippocampal CA1 pyramidal neurons. Neuron 21:1189-1200.

Golding NL, Kath WL, Spruston N (2001) Dichotomy of action-potential backpropagation in CA1 pyramidal neuron dendrites. J Neurophysiol 86:2998-3010.

Goldman-Rakic PS (1995) Cellular basis of working memory. Neuron 14:477-485.

Gonzalez-Burgos G, Barrionuevo G (2001) Voltage-gated sodium channels shape subthreshold EPSPs in layer 5 pyramidal neurons from rat prefrontal cortex. J Neurophysiol 86:1671-1684.

Gorelova NA, Yang CR (2000) Dopamine D1/D5 receptor activation modulates a persistent sodium current in rat prefrontal cortical neurons in vitro. J Neurophysiol 84:75-87.

Gulledge AT, Jaffe DB (1998) Dopamine decreases the excitability of layer V pyramidal cells in the rat prefrontal cortex. J Neurosci 18:9139-9151.

Gulledge AT, Jaffe DB (2001) Multiple effects of dopamine on layer V pyramidal cell excitability in rat prefrontal cortex. J Neurophysiol 86:586-595.

Häusser M, Stuart G, Racca C, Sakmann B (1995) Axonal initiation and active dendritic propagation of action potentials in substantia nigra neurons. Neuron 15:637-647.

Häusser M, Major G, Stuart GJ (2001) Differential shunting of EPSPs by action potentials. Science 291:138-141.

Jaffe DB, Johnston D, Lasser-Ross N, Lisman JE, Miyakawa H, Ross WN (1992) The spread of $\mathrm{Na}^{+}$spikes determines the pattern of dendritic $\mathrm{Ca}^{2+}$ entry into hippocampal neurons. Nature 357:244-246.

Jung HY, Mickus T, Spruston N (1997) Prolonged sodium channel inactivation contributes to dendritic action potential attenuation in hippocampal pyramidal neurons. J Neurosci 17:6639-6646.

Kim HG, Connors BW (1993) Apical dendrites of the neocortex: correlation between sodium- and calcium-dependent spiking and pyramidal cell morphology. J Neurosci 13:5301-5311.

Larkum ME, Zhu JJ, Sakmann B (1999a) A new cellular mechanism for coupling inputs arriving at different cortical layers. Nature 398:338-341.

Larkum ME, Kaiser KM, Sakmann B (1999b) Calcium electrogenesis in distal apical dendrites of layer 5 pyramidal cells at a critical frequency of back-propagating action potentials. Proc Natl Acad Sci USA 96:14600-14604.

Larkum ME, Zhu JJ, Sakmann B (2001) Dendritic mechanisms underlying the coupling of the dendritic with the axonal action potential initiation zone of adult rat layer 5 pyramidal neurons. J Physiol (Lond) 533:447-466.

Linden DJ (1999) The return of the spike: postsynaptic action potentials and the induction of LTP and LTD. Neuron 22:661-666.

Magee JC, Carruth M (1999) Dendritic voltage-gated ion channels regulate the action potential firing mode of hippocampal CA1 pyramidal neurons. J Neurophysiol 82:1895-1901.

Maurice N, Tkatch T, Meisler M, Sprunger LK, Surmeier DJ (2001) D1/D5 dopamine receptor activation differentially modulates rapidly inactivating and persistent sodium currents in prefrontal cortex pyramidal neurons. J Neurosci 21:2268-2277.

Penit-Soria J, Audinat E, Crepel F (1987) Excitation of rat prefrontal cortical neurons by dopamine: an in vitro electrophysiological study. Brain Res 425:263-274.

Sah DW, Bean BP (1994) Inhibition of P-type and N-type calcium channels by dopamine receptor antagonists. Mol Pharmacol 45:84-92.

Schiller J, Helmchen F, Sakmann B (1995) Spatial profile of dendritic calcium transients evoked by action potentials in rat neocortical pyramidal neurones. J Physiol (Lond) 487:583-600. 
Schiller J, Schiller Y, Stuart G, Sakmann B (1997) Calcium action potentials restricted to distal apical dendrites of rat neocortical pyramidal neurons. J Physiol (Lond) 505:605-616.

Schwindt PC, Crill WE (1997) Local and propagated dendritic action potentials evoked by glutamate iontophoresis on rat neocortical pyramidal neurons. J Neurophysiol 77:2466-2483.

Seamans JK, Gorelova NA, Yang CR (1997) Contributions of voltage-gated $\mathrm{Ca}^{2+}$ channels in the proximal versus distal dendrites to synaptic integration in prefrontal cortical neurons. J Neurosci 17:5936-5948.

Seamans JK, Durstewitz D, Christie BR, Stevens CF, Sejnowski TJ (2001) Dopamine D1/D5 receptor modulation of excitatory synaptic inputs to layer V prefrontal cortex neurons. Proc Natl Acad Sci USA 98:301-306.

Shi WX, Zheng P, Liang XF, Bunney BS (1997) Characterization of dopamine-induced depolarization of prefrontal cortical neurons. Synapse 26:415-422.

Spruston N, Schiller Y, Stuart G, Sakmann B (1995) Activity-dependent action potential invasion and calcium influx into hippocampal CA1 dendrites. Science 268:297-300.

Stuart G, Häusser M (1994) Initiation and spread of sodium action potentials in cerebellar Purkinje cells. Neuron 13:703-712.

Stuart G, Häusser M (2001) Dendritic coincidence detection of EPSPs and action potentials. Nat Neurosci 4:63-71.

Stuart G, Schiller J, Sakmann B (1997) Action potential initiation and propagation in rat neocortical pyramidal neurons. J Physiol (Lond) 505:617-632.

Stuart GJ, Sakmann B (1994) Active propagation of somatic action potentials into neocortical pyramidal cell dendrites. Nature 367:69-72.
Stuart GJ, Dodt HU, Sakmann B (1993) Patch-clamp recordings from the soma and dendrites of neurons in brain slices using infrared video microscopy. Pflügers Arch 423:511-518.

Tsay D, Yuste R (2002) Role of dendritic spines in action potential backpropagation: a numerical simulation study. J Neurophysiol 88:2834-2845.

Vetter P, Roth A, Häusser M (2001) Propagation of action potentials in dendrites depends on dendritic morphology. J Neurophysiol 85:926-937.

Wang J, O’Donnell P (2001) D1 dopamine receptors potentiate NMDAmediated excitability increase in layer $\mathrm{V}$ prefrontal cortical pyramidal neurons. Cereb Cortex 11:452-462.

Watanabe M, Kodama T, Hikosaka K (1997) Increase of extracellular dopamine in primate prefrontal cortex during a working memory task. J Neurophysiol 78:2795-2798.

Williams SR, Stuart GJ (1999) Mechanisms and consequences of action potential burst firing in rat neocortical pyramidal neurons. J Physiol (Lond) 521:467-482.

Williams SR, Stuart GJ (2000) Backpropagation of physiological spike trains in neocortical pyramidal neurons: implications for temporal coding in dendrites. J Neurosci 20:8238-8246.

Williams SR, Stuart GJ (2002) Dependence of EPSP efficacy on synapse location in neocortical pyramidal neurons. Science 295:1907-1910.

Yang CR, Seamans JK (1996) Dopamine D1 receptor actions in layers V-VI rat prefrontal cortex neurons in vitro: modulation of dendritic-somatic signal integration. J Neurosci 16:1922-1935. 